\title{
DEFINING KEY DETERMINANTS OF THE STRATEGIC ECONOMIC SECURITY OF THE AGRO-INDUSTRIAL COMPLEX IN TERMS OF STABILIZING POLITICAL COURSE
}

\author{
Yulia $V$ Melnikova ${ }^{1, *}$,Elena A. Posnaya ${ }^{2}$, Boris $A$ Bukach $^{2}$, Anna $V$ Shokhnekh ${ }^{1}$, and Sergey $V$ Tarasenko $^{2}$ \\ ${ }^{1}$ Volgograd State Socio-Pedagogical University, Volgograd, Russia \\ ${ }^{2}$ Sevastopol State University, Sevastopol
}

\begin{abstract}
The key determinants of the strategic economic security of the agro-industrial complex in the conditions of a stabilizing political course on food security ensure the state of the facility in which it is possible to carry out conceptual and functional actions built on goals and principles. The composition and structure of the agro-industrial complex of the state is multicomponent and systemic, it contains many internal connecting blocks and interdependent structures. The uneven development of some agricultural systems occures in the lag of technologies and assortment content. Disruptions in supply and marketing, as well as emergency circumstances cause crop failure, cattle death, which significantly affects the systemic component of economic security. A decrease in food security leads to a decrease in the country's food security due to the decline in the development of an entire industry.
\end{abstract}

\section{Introduction}

The authors suggest that ensuring economic security as a continuous and dynamic process of management control function is aimed at the most efficient use of production resources to prevent threats and effectively solve problems. It causes constant implementation of measures that stabilize the functioning of financial and economic activities on the basis of the application of scientific and technical achievements with the goal of sustainable development of the economic entity.

The determination of the key determinants of the strategic economic security of the agricultural sector will ensure implementing of the subject's activities aimed at generating income in the agricultural sector, taking into account the stabilization policy. "Ensuring economic security" as a term indicates the process in which the subject is in order to maintain the position of "economic security".

Forming economic security system in the digital economy involves the study of all situations, units and categories, as well as causal relations with other processes of business entities. The perception of techniques, technologies, digitalization processes, understanding and identification of threats to entrepreneurial thinking has a key role in the management decision-making processes of agricultural organizations of the agro-industrial complex. New areas in the study of the nature of electronic digital language units, their features, functional and system status are being discovered.

\section{Discussion}

Ontology for ensuring economic security is represented as:

1) the process during which main directions of economic security are implemented to prevent potential damage and achieve the maximum level of economic security, both now and in the future [Burtsev Yu.A., 2017, P.73]; 2) the process of creating favorable conditions under which the interests are respected and the organization's goals are achieved [Kuznetsova EI, 2011, P.42];

3 ) process of preserving and increasing the property of the subject, as well as maintaining a business reputation and stable functioning in a competitive environment [Yuhtanova Yu.A., 2018, P.107];

4) conducting an independent economic policy in accordance with the national interests of the country, which is based on a synthesis of the market mechanism and state regulation of the economy [Isaeva A.A., 2019, P.105];

5) active process to protect a business entity from internal and external threats and create conditions of existence that guarantee possibility of its stable development [Moiseeva V. M., 2015, P.82].

However, ensuring economic security is complicated by the need to integrate agricultural organizations into the digital communications field as the need to unlock potential in the context of rapidly developing technologies in all sectors of the economy.

But fast integration into the digital field does not occur in Russia. Given the huge size and diversity of the

\footnotetext{
* Corresponding author: julmeln@gmail.com
} 
territories of Russia, as well as the variety of traditions that determine needs of the population, digital information and communication field should be formed as a state initiative in promoting innovation. State initiative in sectors of the economy, especially in the business environment, is accompanied by risks in promoting innovation. That is why the issues of ensuring economic security in the digital economy are becoming especially relevant.

Another problem is that organizations of the agroindustrial complex of Russia are not ready for development in the digital communication information field compared with other developed countries. In the electronic and digital environment, agricultural organizations in any legal form of business can quickly organize and flexibly respond to various changes and needs of society, which occur in constantly changing and growing demands. Digital economy dictates new ways of doing business, where it is impossible to carry out activities without using an electronic and digital environment. E-commerce, web-positioning of business types, the use of digitalization, electronic-digital reporting, web-training are becoming main electronic and digital platforms and operations.

\section{Materials and methods}

To test the proposed hypothesis, a statistical analysis and synthesis of ontological approaches to innovation and investment policy are used. The study of the process of ensuring economic security will allow us to synthesize and expand a new apparatus of terminological concepts of the digital economy of the generation and integration electronic-digital ability of economic entities. The processes of thinking about the experience of the digital world, about the opportunities that open up, about consumers and business partners in the digital economy have an impact on the integration routes into the electronic-digital field of economic entities of various sectors of the economy. Concepts' definition that reflect the basic processes of world perception and attitude in the electronic digital environment (auditory and visual activity; mental activity; speech activity in the form of a lexical and phraseological platform) will allow us to build a mechanism for effective integration of food industry entities into the digital economy. From the perspective of the economic security of economic entities in the food sector, it is impossible to carry out facts of economic life without the use of an electronic and communicative environment.

\section{Research part}

E-commerce, web-positioning of activities in the food sector, the use of digitalization, electronic-digital reporting, web-training are becoming integral parts of electronic and digital platforms and operations in the activities of business entities of various economy sectors [G. Brutyan, 1976; Guseva A.E., 2007; Mishankina N.A., 2010; Shokhneh A.V., Telyatnikova V.S.,
Nasonova L.I., 2018; Rogachev A.F., Mazaeva T.I., Shokhnekh A.V., 2016].

It should be noted that today there is a particularly high attention to the problems of the agricultural sector in the structure of the agro-industrial complex (AIC), which ensures food security and independence.

Studies show that the agricultural sector is directly affected by abnormal weather events, instability of the environment, changes in magnetic fields, pollution of soils, water and air due to the burning of fossil fuels and human industrial activities. The variety of agricultural components can be roughly divided into three largescale, but closely related subsystems: industrial production in the interests of the agricultural industry; agriculture as a separate industry producing specific products; its subsystem for processing, marketing and promoting agricultural products.

The first subsystem includes all sectors of the economy that fully or partially provide agribusiness with means of production, as well as all enterprises that provide services for the sale, repair and maintenance of agricultural production and technical equipment. Most often this is engineering, the production of sorting and packaging equipment, the production of fertilizers and plant protection products, veterinary preparations and much more.

The issue of modernizing the agro-industrial complex and introducing innovations as key determinants of strategic economic security expects the disclosure of the concepts: "production and technical equipment"; "strengthening the material base"; "digitalization and robotization of the agricultural sector." This is precisely what the first subsystem of the agroindustrial complex is called upon to do in the whole complex of measures for the reintroduction of the sphere and the economic breakthrough. Without a full-fledged base for the industrialization of the sphere, the competent work of the other two agro-industrial complex's subsystems is at risk.

The second subsystem consists of all organizations and individuals directly involved in the production of agricultural products. First of all, these are state agricultural enterprises, farmers, combined agricultural collectives, the growth of which is observed everywhere. The main burden on the development of the agroindustrial complex lies precisely on the shoulders of those who work on the earth, increase its wealth, work to improve the quality of products and increase the productivity of available capacities.

The third subsystem includes competent labor resources - "processing, storage and marketing", and directly depends on the effect the second subsystem's production - "agricultural production".

The determinants of economic security appear in the areas of primary processing of agricultural products, harvesting, bringing farmers' products to the final consumer. In this chain, the innovative development of a system synthesizing production becomes significant:

- gustatory;

- meat and dairy;

- fish;

- flour and cereal; 
Table 1. Determinants of the strategic economic security of the country.

\begin{tabular}{|l|l|l|l|}
\hline № & \multicolumn{1}{|c|}{ Determinants + } & \multicolumn{1}{c|}{ Determinants - } & \multicolumn{1}{c|}{ Future determinants } \\
\hline 1 & $\begin{array}{l}\text { Unlimited potential of modern } \\
\text { agricultural business }\end{array}$ & $\begin{array}{l}\text { Uncertainty of agro-industrial } \\
\text { development priorities }\end{array}$ & $\begin{array}{l}\text { Production cooperation of agricultural } \\
\text { producers and the development of financial ties }\end{array}$ \\
\hline 2 & $\begin{array}{l}\text { Development of state target } \\
\text { programs }\end{array}$ & $\begin{array}{l}\text { No connections with related } \\
\text { industries }\end{array}$ & $\begin{array}{l}\text { Improving the investment climate in the field of } \\
\text { agricultural business }\end{array}$ \\
\hline 3 & $\begin{array}{l}\text { Providing the population with } \\
\text { quality products }\end{array}$ & $\begin{array}{l}\text { Inefficiency of investment } \\
\text { activity in the agricultural } \\
\text { sector }\end{array}$ & $\begin{array}{l}\text { Development of the market structure "from } \\
\text { field to counter" }\end{array}$ \\
\hline 4 & $\begin{array}{l}\text { System of preferential loans for } \\
\text { agricultural producers }\end{array}$ & $\begin{array}{l}\text { Inovative and technological } \\
\text { update is at a slow pace }\end{array}$ & $\begin{array}{l}\text { Improving the procurement and supply system } \\
\text { through the state orders system }\end{array}$ \\
\hline Source: made by authors & \\
\hline
\end{tabular}

- compound feed industry;

- crop production;

- gardening;

- preservation;

- frosts.

The third sphere also includes retail trade in food products and the field of catering. The sectors of the third sphere of the agro-industrial complex provide primary industrial processing of agricultural raw materials, especially perishable ones, and their delivery to the consumer.

The entire powerful structure of the agro-industrial complex is designed to fulfill enormous social and economic importance - to provide the state population with high-quality and diverse food products (food security), support export of a number of goods (grain, sugar beets, dairy products), provide jobs to people employed in the agricultural sector and their decent income.

At the same time, it should be noted that food security is a part of the state's economic security structure and directly affects its stability.

There can be distinguished a number of aspects (determinants) that currently have a significant impact on economic security. In the data system of specific factors that generate and determine the phenomenon, it is possible to distinguish bipolar determinants that have both positive and negative inhibitory effects on the strategic economic security system (Table 1).

The key determinants of the strategic economic security of the agro-industrial complex determine the directions of research on favorable and unfavorable indicators in the model of ensuring strategic economic security from the perspective of the state of the innovation environment of agricultural organizations (further referred to as IEAO). The state of the innovation environment must begin with the diagnosis [Shokhnekh A.V., 2020; Melnikova Y.V.,2020]:

1) an indicator of the entrepreneurial resources of IEAO: owners of agricultural organizations applying innovations, or seeking to use an innovative product (a good, work, service);

2) an indicator of the intellectual resources of IEAO: technological documentation, patent, license, business plans for the development of innovations, or an innovation program;
3) the indicator of material resources of the IEAO: experimental instrumentation base, modernized technological and information equipment, commercial real estate resource;

4) IEAO finance from internal and external sources: structure of own and borrowed sources, trust funds and other subsidies for investment factors;

5) the indicator of human resources IEAO: create a leader who can bring innovative technologies into the workflow, build a team based on innovative leadership potential; set partnership and personal relations of employees with research centers and educational institutions; experience in commercializing innovations and experience in team project management in investment activities;

6) IEAO infrastructure resources indicator: marketing research department for the implementation of innovative market research projects; patent legal regulation of innovation issues; information and communication structure of IEAO; Department of Innovative Research and Testing of Results; schools of consumers and manufacturers of an innovative product (a good, work, service) for investment justification;

7) indicator of investment resources of innovative development of IEAO projects: investors who receive part of the profit as a result of the introduction of an innovative product (a good, work, service) for concluding an investment agreement [Kornilova LM, Ivanov EA, Ivanov PA 2018].

Information indicators in the model of ensuring economic security for a financial assessment of the IEAO attractiveness should include an analysis of the level of favorable innovativeness of the state (external direct effects on IEAO). An innovative state involves active interaction with innovative business structures of large, medium and small enterprises in order to create favorable conditions. The evolution of innovative systems shows the priority of state policies in developed countries.

External innovation environment as a set of institutional units and driving forces for IEAO, which has an impact through the mechanisms of direct and indirect impact in the development of the digital economy.

All the many environmental factors of IEAO in the model of ensuring strategic economic security can be combined into two groups: 


\section{The consistency and component nature of the IEAO external environment appears in many reasons that affect the possibility of using versatile types of innovative activity, the products of which quickly lose relevance as a result of use, as they quickly become obsolete due to the many techno-digital innovations \\ The instability of state law regulation of IEAO as a response to the latest technological installations in the development of information and communication structures, causing mobility (dynamism) in the context of digital transformation \\ Uncertainty in IEAO depends on the volume and truthfulness of the information available to an innovative business entity regarding the $x$-factor of the external environment in the context of digital transformation}

The external nature of IEAO is shown by external effects (both positive and negative) from the impact of innovative phenomena, processes and products on external environmental factors and the overall development of national and world economies in the context of digital transformation

The strength of correlation in IEAO shows the degree of impact when replacing one factor with other factors that form the innovative environment in the context of digital transformation

Fig. 1. Quality criteria for a favorable IEAO in the model of ensuring strategic economic security.

1) directly affecting the IEAO in the development of the digital economy: legal regulation of state, public and entrepreneurial mechanisms for applying innovations; reforming educational state programs for technology for resource conservation, recycling and modification; the presence of regular suppliers of quality raw materials; availability of consumers of innovative products; competitive environment; alternative products (goods, works, services); trading partners; financial intermediaries; intermediaries providing services to infrastructure industries;

2) indirectly influencing IEAO in the development of the digital economy (state of the economy, scientific and technological progress, demographic, natural, political and cultural influences, ethical and environmental factors).

\section{Final part}

The formation of an external favorable innovation environment for IEAO is based on government programs that stimulate innovative business structures.

Qualitative criteria for a favorable IEAO in the model for ensuring strategic economic security are stated as indicators of a financial assessment of an agricultural organization, including: 1) systematic and component nature - the versatility of IEAO; 2) instability - mobility IEAO; 3) IEAO uncertainty; 4) the externality of InnSrSKH; 5) the strength of IEAO connections (Figure 1).
Therefore, the innovative indicators of IEAO in the model of ensuring strategic economic security (due to digital transformation) should include:

1) indicators of markets in the digital economy, selforganizing based on proposals and segment requests for IEAO;

2) indicators of shareholders' requests for dividends and exercise of property rights taking into account the availability of information for IEAO;

3 ) indicators of legislative mechanisms of the federal, regional and local level in the context of cyclical transformation, including tax requirements for IEAO;

4) indicators of counterparties in the digital economy, in relation to which there are obligations or requirements for IEAO;

5) indicators of changing equipment and technologies in digital transformation to the quality and demand for products (goods, works, services) of IEAO;

6 ) indicators of personnel training for the educational level of labor resources competencies, limited by technological transformation for IEAO;

7) trends indicators of requests growth in terms of labor resources informatization - hired workers for IEAO;

8) indicators of the current and forecasted activities of competitors in the context of circular and technological transformation of markets for IEAO;

9) indicators of the possible turbulent state in the conditions of cyclical and technological transformation, which determines the consequences of economic crises for innovative entrepreneurship of agricultural organizations; 
10) indicators of information throughput capacity in the conditions of informatization and digital transformation, allowing you to quickly and accurately make a managerial decision in IEAO, as well as coordinate the process of achieving strategies.

High risks of innovation in the model of ensuring strategic economic security are determined by how dynamic the environment is due to technological transformation. Innovative phenomena, processes and products in IEAO can change with the speed of the turbulent position, but also more slowly, showing signs of predictable balance.

The innovative products of the 21 st century and the processes of organizing production of IEAO in the model for ensuring strategic economic security are characterized by:

1) an indicator of the short life cycle of an innovative product (a good, work, service) and IEAO itself in circular economy;

2) an indicator of a limited period of time due to technological transformation of the development of innovative products, equipment, technologies for IEAO in the digital economy;

3) an indicator of the conditions for creating a cooperative partnership between the state and business structures, prices are not the main attribute - the essence of cluster cooperation in the digital economy management system;

4) an indicator of the reduction of large corporations with a pyramidal structure and their reorganization in IEAO in conditions of technological transformation;

5) an indicator of the application of outsourcing of expert work on the conformity of an innovative product (a good, work, service) to market demand for IEAO in a circular economy management system;

6) an indicator of a decrease in the volume of mass production in IEAO, for the implementation of which it takes a long period of time (over this period, the innovation may die and become unclaimed) in terms of technological transformation;

7) an indicator of the reduction of large storage facilities in IEAO for the storage of raw materials and finished products in the digital economy;

8 ) an indicator of implementing the job order method of working with customers and consumers of innovations for IEAO in the system of managing a circular economy.

The global trend of revitalizing IEAO is carried out from the standpoint of resource conservation and modification, subject to cyclical transformations.

When coming to conclusions, it should be noted that innovation and investment indicators in the model of ensuring economic security, considering the management of circular economy, should include a group of parameters for maneuvering IEAO entrepreneurship under the influence of the external environment. The dividing boundary of the internal environment can lay estimates: of the physical component (it limits the territory of the innovative subject); organizational component (differences in the form of management, the amount of salaries, social conditions); branding and image (the choice of strong and successful agricultural organizations in the agricultural sector).

While analyzing financial indicators of investment attractiveness, the indicators include not only financial indicators, but also a wider range of values, which do not necessarily have a quantitative measurement in the model of ensuring strategic economic security. IEAO economic security indicators set the range of targeted use of investment resources for the implementation of the project and profit. Such a range in a simplified form can be formed in terms of the quality of diagnostics of three main groups: IEAO management (competencies), IEAO owners (requests and interests), IEAO investors (financial viability and investment mobility).

The indicators of IEAO in the model of ensuring strategic economic security are based on scientific methods: forecasting the possibility of an agricultural investment organization implementing an innovation and investment project; analysis of the targeted use of investment and production resources to create an innovative product IEAO; evaluation of target marketing activities of IEAO.

There is a growing need to implement strategic economic security, which can be done by evaluating financial results and ratios in a cyclical economy, namely: 1) the liquidity and solvency of invested agricultural organizations in IEAO; 2) the effectiveness of the management of agricultural organizations in IEAO; 3) the profitability of the investment activity of agricultural organizations of the agro-industrial complex in IEAO.

Eliminating threats that involve the onset of risk is dictated by the very essence of the security process, and is also confirmed normatively in the state standard of Russia GOST R 51898-2002 "Safety Aspects. Rules for inclusion in standards. "In this standard, security is interpreted from the perspective of the state of the subject in which there is no unacceptable risk, and the safe position itself is achieved by reducing the level of risk to insignificant as an acceptable risk. The model of strategic economic security includes procedures to promote and protect the innovation environment, which determines the application of analytical procedures for the financial assessment of investment attractiveness in circular economy (Figure 2).

A key condition for the formation of an innovation environment (IEAO) is the internal self-organization of the generation, harmonization and implementation of innovations. The innovative potential of the internal environment of IEAOis a crucial factor when creating innovative agricultural entrepreneurship, but it is insufficient as a condition for the effective commercialization of scientific and technical activities and the implementation of innovative breakthrough strategies.

\section{Conclusion}

In conclusion, it should be noted that in the model of ensuring economic security, defining key determinants 


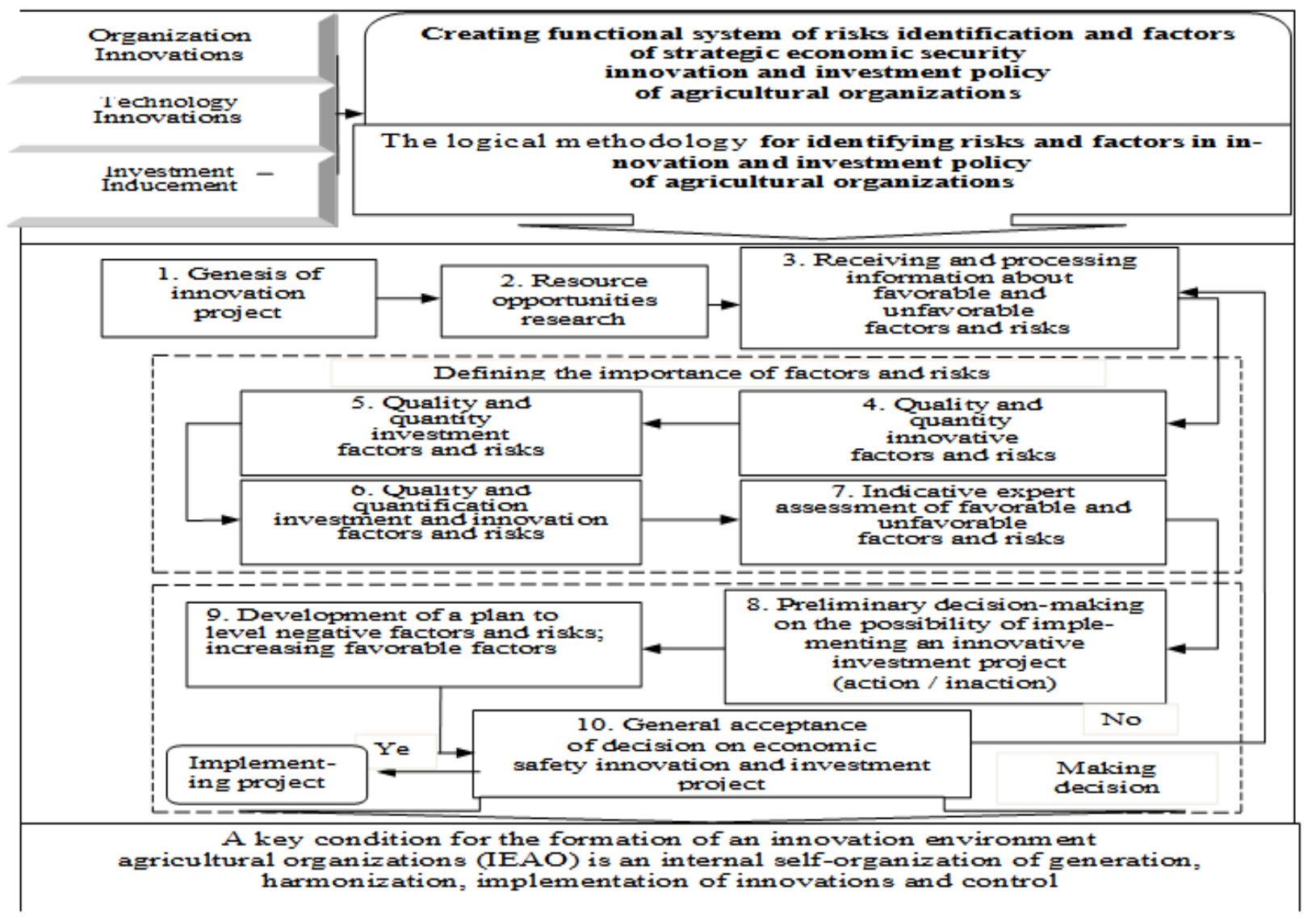

Fig. 2. Model for ensuring strategic economic security of the innovation and investment policy of agricultural organizations in the agricultural sector (Source: compiled by the authors).

of the strategic economic security of the agro-industrial complex in the context of a stabilization policy allows: - firstly, to start the risk leveling process (identification and reduction of the risk level) based on systematically organized procedures (processes) to minimize the risk to a certain limit;

- secondly, to recognize the positive flow of information, identifying favorable factors that determine the route of sustainable development of agricultural organizations of the agro-industrial complex in terms of technological transformation.

\section{References}

[1] Yu.A. Burtsev, L.N. Romanchenko, The process of ensuring the economic security of the enterprise, Successes in modern science and education, 6, 4, 72-75 (2017).

[2] E.I. Kuznetsova, D.V. Belkin, Economic security of the enterprise: condition or process?, Bulletin of Moscow University of the Ministry of Internal Affairs of Russia, 6, 40-45 (2011).

[3] Yu.A. Yukhtanova, D.G. Bakharev, Study of the concept and factors of enterprise performance in the context of ensuring its economic security, Business security as a factor in combating fraud. Materials of the International scientific-practical conference, 106-110 (2018).
[4] A.A. Isaeva, The history of forming and definition of the term "economic security" and alternative approaches of the classics and Keynesians to its maintenance, Scientific potential of the XXI century, 104-107 (2019).

[5] V.M. Moiseeva, The content of interpretations of the uncertainty concept in ensuring economic security, Scientific and methodological electronic journal "Concept", 23, 81-85 (2015).

[6] G.A. Brutyan, The linguistic picture of the world and its role in cognition, Methodological problems of language analysis (Yerevan: Publishing House of Yerevan University, 294, 1976).

[7] A.E. Guseva, Fundamentals of linguo-cognitive modeling of lexical and phraseological fields in German and Russian (M.: Publishing House of Moscow State Educational Institution, 362, 2007).

[8] N.A. Mishankina, Linguo-cognitive modeling of scientific discourse, Abstract of diss. Doctor of Philology (2010) [Electronic resource]. Available at: http://www.dissercat.com/content/lingvokogni tivnoe-modelirovanie-nauchnogo-diskursa.

[9] A.V. Shokhnekh, V.S. Telyatnikova, L.I. Nasonova, Digital economy: theory and methodology of integration of subjects in the electronic digital entrepreneurial field: monograph (Ufa: AETERNA, 170, 2018). 
[10] Y.V. Melnikova, A.V. Shokhnekh, Forming the policy of insurance of innovative and investment activities of agricultural organizations as a concept-strategy of provision of economic and food security, Lecture Notes in Networks and Systems (87, 809-816, 2020).

[11] A.V. Shokhnekh, Y.V. Melnikova, T.M. Gamayunova, The investment concept strategy of development of innovative activities of agricultural organizations in the conditions of techno-economic modernization, Lecture Notes in Networks and Systems (87, 796-808, 2020).

[12] L.M. Kornilova, E.A. Ivanov, P.A. Ivanov, Stimulation of innovative activity of agricultural organizations - the basis of the digitalization of the agro-industrial complex, Innovative development of the economy, 5, 47, 52 (2018).

[13] A.F. Rogachev, T.I. Mazaeva, A.V. Shokhnekh, Manufacturing and consumption of agricultural products as a tool of food security management in Russia, Revista Galega de Economia, 25, 2, 87-94 (2016). 